archives

of thermodynamics

Vol. 36(2015), No. 3, 149-160

DOI: $10.1515 /$ aoter-2015-0027

\title{
Experimental and numerical investigation of thermal flow meter
}

\author{
ARTUR CEBULA ${ }^{1}$ \\ Cracow University of Technology, Institute of Thermal Power Engineering, \\ al. Jana Pawła II 37, 31-864 Kraków, Poland
}

\begin{abstract}
The paper presents analytical and numerical model calculation results of the temperature distribution along the thermal flow meter. Results show a very good conformity between numerical and analytical model. Apart from the calculation results the experimental investigations are presented. The author performed the test where a temperature of duct wall surface was measured. Therelation between mass flow rate in terms of the duct surface temperature difference was developed.
\end{abstract}

Keywords: Mass flow meter; Heat transfer; Uniform heat flux; Thermal model

\section{Introduction}

Thermal flow meters find their application in various industrial branches like automotive, chemical, medical, aerospace, and others [1].There are three types of thermal flow meters. The first group of flow meters called 'hotwire and hot-film' measure the effect of the flowing fluid on hot body. The second kind are thermal flow meters, called 'calorimetric flow meters', that measure the asymmetry of temperature profile around heated body [2]. The third group of flow meters measure the time lapse of a heated pulse over a known distance. Th most cases thermal flow meters are used to measure and control gas flow. The wide range of research were performed in the case of gases [3], and there is a small number of papers related to liquids. The flow meter that is analyzed belongs to the second group. The operating

${ }^{1}$ E-mail: acebula@pk.edu.pl 
principle of the analyzed flow meter is based on the heat transfer between the pipe wall and flowing liquid and the measured quantity is the temperature difference between two points along the pipe. The objectives of this study were to investigate the possibility of application of the thermal flow meter to measure liquid flow with the small rate. Initially, analytical model is presented which is used to calculate temperature distribution along heated part of the duct and not heated part downstream. The numerical model of is described and results between the method are presented. Finally, experimental research results show the obtained dependency for mass flow rate in terms of pipe wall outer surface temperature difference. Additionally, numerical model validation against the measured data is presented.

\section{Analytical model}

The analytical model of the thermal flowmeter was developed. The cylindrical duct of inner radius $r$ was considered. The uniform heat flux is prescribed on a part of the duct with length $l=x_{1}$. It was assumed that the duct wall has a very low thickness and is made of a material with high thermal conductivity, therefore temperature drop across the duct wall was neglected. These assumptions allow to utilize the analytical model to determine duct wall temperature.

A laminar forced convection flow with a fully developed laminar velocity profile is analyzed. Fluid flows in an axial direction along $x$ axis (Fig. 1). For $x<0$ fluid and wall have the same uniform temperature $t_{i n}$ and heat flux set on the outer surface is zero. For $0<x<x_{1}$ the heat flux, $\dot{q}$, is equal to $\dot{q}=\dot{q}_{I}$ and for $x>x_{1}$ the outer wall is adiabatic as in case when $x<0$.

By the use of analytical model, the wall temperature was calculated for $x>0$ for both region where uniform heat flux is prescribed and for $x>x_{1}$ where outer wall is adiabatic. Siegel et al. [4] derived a formula for the longitudinal variation of wall temperature, $t_{w}$, that was loaded by uniform heat flux, $\dot{q}$, on the overall duct length. The wall temperature distribution for fully-developed flow describes the formula

$$
\theta=\left(t_{w}-t_{i n}\right)=\frac{\dot{q} r_{0}}{k}\left[\frac{4 x / r_{o}}{\operatorname{RePr}}+\frac{11}{22}+\sum_{n=1}^{\infty} C_{n} \exp \left(-\frac{\beta_{n}^{2}}{\operatorname{RePr}} \frac{x}{r_{o}}\right) R_{n}\left(r / r_{o}\right)\right]
$$




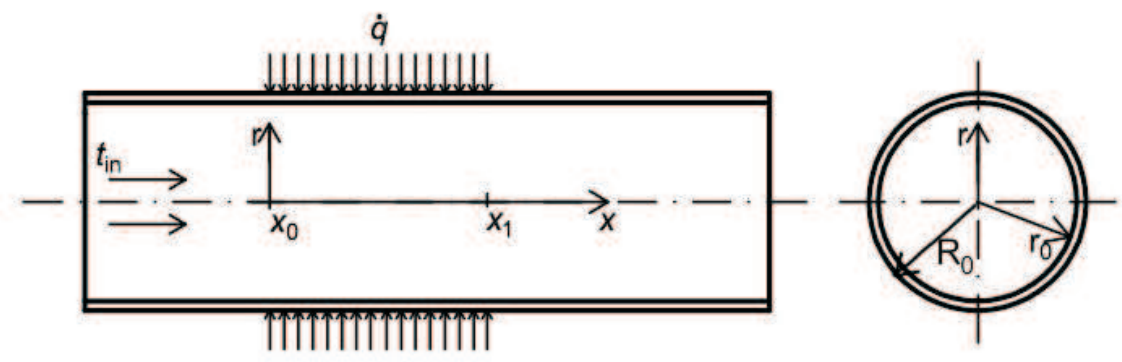

Figure 1: Circular duct model.

where: $x$ - axial coordinate, $\mathrm{m} ; k$ - thermal conductivity, $\mathrm{W} / \mathrm{mK} ; \mathrm{Pr}-$ Prandtl number $c_{p} \mu / k\left(c_{p}\right.$ - specific heat, $\mathrm{J} / \mathrm{kg} \mathrm{K} ; \mu$-dynamic viscosity, $\left.\mathrm{Ns} / \mathrm{m}^{2}\right) ; \operatorname{Re}-$ Reynolds number $u 2 r_{o} / v(u$ - velocity, $\mathrm{m} / \mathrm{s} ; v$ - kinematic viscosity, $\left.\mathrm{m}^{2} / \mathrm{s}\right) ; r$ - radial coordinate; $r_{o}$ duct radius, $\mathrm{m} ; t$ - temperature: $t_{w}$ - duct wall temperature, $t_{i n}$ - fluid temperature at duct inlet, $\mathrm{K}$.

The quantities $\beta_{n}^{2}, R_{n}\left(r / r_{o}\right), C_{n}$ are the eigenvalues, eigenfunctions and constant, respectively. Values of these quantities were evaluated by Hsu [6] for $n=1-15$ and are presented in Tab. 1.

In the analyzed case, heat flux value is equal to $\dot{q}$ on the part of the duct up to the length $x_{1}$. Beyond this length the heat flux is equal to 0 . However. wall temperature distribution is calculated by the formula (1) and with the use of superposition principle.

The solution of the problem can be determined by summing up the solutions of partial problems with the boundary condition of the 2nd kind (heat flux) as shown in Fig. 2. The boundary condition has the form:

$$
\begin{gathered}
\dot{q}(x)=\dot{q}_{I}, \quad 0<x<x_{1}, \\
\dot{q}(x)=\dot{q}_{I I}=-\dot{q}_{I}, \quad x_{I}<x<x_{2} .
\end{gathered}
$$

Once we account for the formula (1) and decompose the heat flux into two components (Fig. 2), the wall temperature $\theta=t_{w}-t_{\text {in }}$ can be expressed as follows:

$$
\begin{gathered}
\Delta T_{I}=\frac{\dot{q}_{I} r_{0}}{k}\left[\frac{4 x / r_{o}}{\operatorname{RePr}}+\frac{11}{22}+\sum_{n=1}^{\infty} C_{n} \exp \left(-\frac{\beta_{n}^{2}}{\operatorname{RePr}} \frac{x}{r_{o}}\right) R_{n}(1)\right], \\
\Delta T=\Delta T_{I}, \quad 0<x<x_{1},
\end{gathered}
$$


Table 1: The eigenvalues and constant for Eq. (8).

\begin{tabular}{|c|c|c|c|}
\hline$n$ & $\beta_{n}^{2}$ & $\mathrm{Rn}$ & $C_{n}$ \\
\hline 1 & 25.6796 & -0.492517 & 0.40348 \\
\hline 2 & 83.8618 & 0.395509 & -0.17511 \\
\hline 3 & 174.1667 & -0.345874 & 0.10559 \\
\hline 4 & 296.5363 & 0.314046 & -0.07328 \\
\hline 5 & 540.9472 & -0.291251 & 0.05504 \\
\hline 6 & 637.3874 & 0.273807 & -0.04348 \\
\hline 7 & 855.8495 & -0.259853 & 0.03560 \\
\hline 8 & 1106.3290 & 0.248332 & -0.02991 \\
\hline 9 & 1388.8226 & -0.238590 & 0.02564 \\
\hline 10 & 1703.3278 & 0.230199 & -0.02233 \\
\hline 11 & 2049.8430 & -0.222863 & 0.01971 \\
\hline 12 & 2438.3668 & 0.216370 & -0.01758 \\
\hline 13 & 2838.8981 & -0.210566 & 0.01582 \\
\hline 14 & 3281.4362 & 0.205332 & -0.01435 \\
\hline 15 & 3755.9803 & -0.200577 & 0.01310 \\
\hline
\end{tabular}

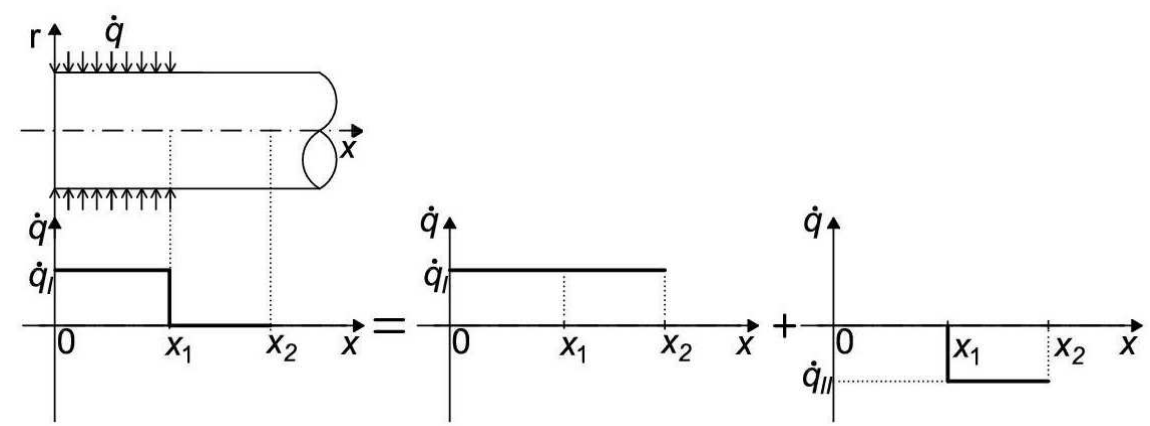

Figure 2: Heat flux division into two components.

$$
\begin{gathered}
\Delta T_{I I}=\frac{-\dot{q}_{I} r_{0}}{k}\left(\frac{4(x-l) / r_{o}}{\operatorname{RePr}}+\frac{11}{22}+\sum_{n=1}^{\infty} C_{n} \exp \left(-\frac{\beta_{n}^{2}}{\operatorname{RePr}} \frac{(x-l)}{r_{o}}\right) R_{n}(1)\right), \\
\Delta T=\Delta T_{I}+\Delta T_{I I}, \quad x_{1}<x .
\end{gathered}
$$

The following relation is valid $\dot{q}=h \Delta T$, where: $h$ - heat transfer coefficient, 
$\mathrm{W} / \mathrm{m}^{2} \mathrm{~K}$. Equations (5) and (7) make it possible to calculate the duct wall temperature when step-function is applied as shown in Fig. 3.

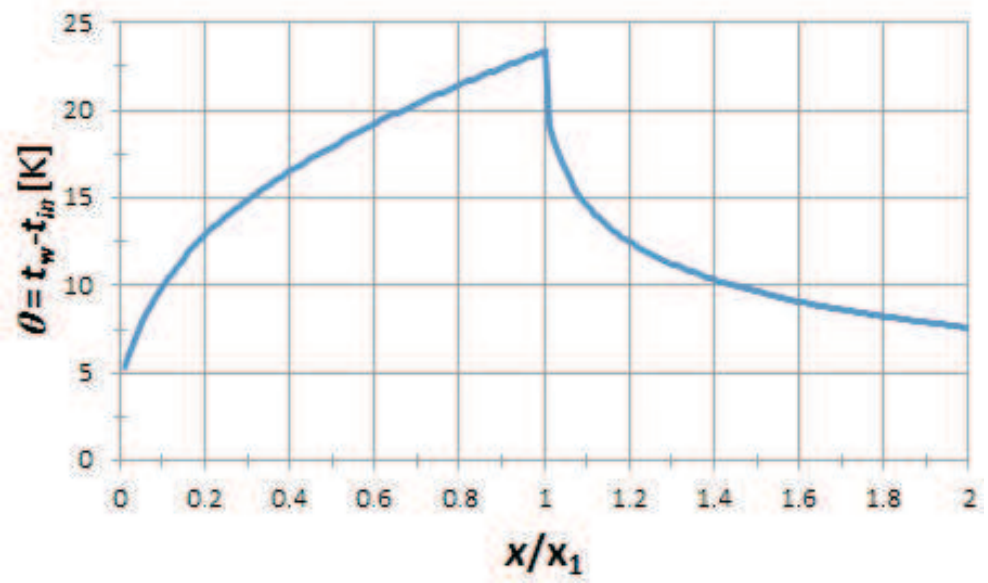

Figure 3: Temperature distribution on the duct wall, $\operatorname{Re}=200$.

Let's consider a flow of water $(\mathrm{Pr}=6.99)$ in laminar fully developed regime Re $=200$ through the pipe of diameter $D=7.0 \mathrm{~mm}$. Heat flux $\dot{q}=$ $15000 \mathrm{~W} / \mathrm{m}^{2}$ is described on the part of the duct up $x / x_{1}=1$. Temperature distribution obtained from Eq. (5) and Eq. (7) is depicted in Fig. 3. The temperature distribution is consistent with expectation, and there is a temperature increase along the heated part of the duct up to $x_{1}$ and wall temperature drop downstream the duct (Fig. 3). Results obtained from the described model are compared with numerical model results to assess the correctness of the numerical model.

\section{Numerical model}

A numerical model was created that make it possible to calculate cylindrical wall temperature on the duct partially loaded with heat flux, $\dot{q}$. The computational domain has two-dimensional axisymmetric geometry. The domain represents straight duct with the length equal to $20 D$ and $5 D$, respectively upstream and downstream to the heated part. The heated part has a length equal to $l$ as it is depicted in Fig. 4.

The grid of the numerical model contains $\sim 10^{5}$ hexahedral control volumes, the final number of control volumes was chosen after the mesh sensitivity calculations. 


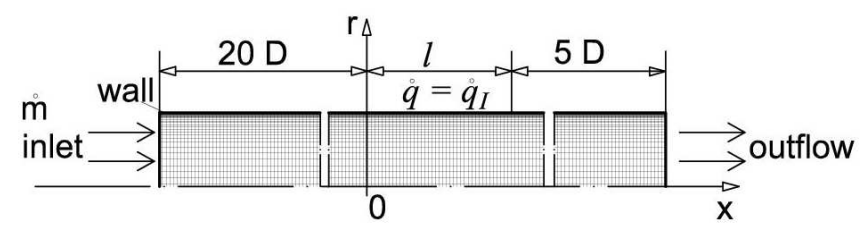

Figure 4: The geometry of numerical model.

The duct walls are set as the adiabatic upstream and downstream the heated part, at inlet the mass flow rate is set, fluid flows with uniform velocity and temperature profile at the inlet. The flow regime is laminar, incompressible with no slip on the walls. Heat flux, $\dot{q}$, boundary condition is defined at the outer wall on $r=R_{o}$ with values $\dot{q}=\dot{q}_{I}$ on section $l$ and $\dot{q}=0$ on the ramming duct part.

Temperature distribution on the duct wall and comparison with the analytical result for two mass flow rates are presented in Fig. 5. Analyses were performed for the model with water as the working fluid with temperature $t_{\text {in }}=10^{\circ} \mathrm{C}$ at the inlet and constant water properties. Heat load was equal to $\dot{q}_{I}=15000 \mathrm{~W} / \mathrm{m}^{2}$. For presented results, the mass flow rate, $\dot{m}$, is equal to $0.96 \times 10^{-3} \mathrm{~kg} / \mathrm{s}$ and $1.36 \times 10^{-3} \mathrm{~kg} / \mathrm{s}$ which corresponds to the value of Re number 180 and 235 respectively.

In Fig. 5 solid line represents numerical solution while the dot line indicates results for the analytical solution. Additionally dashed line shows the difference between temperature obtained from numerical and analytical model, $D T=T_{\text {num }}-T_{\text {analytical }}$, where values are present on vertical axis right hand-side. Similar wall temperature distribution were obtained for both methods. Additionally $D T$ values don't exceed $0.3 \mathrm{~K}$ apart from points $x / l=0$ and $x / l=1$ where wall boundary conditions changes from $\dot{q}=q_{I}$ to $\dot{q}=0$. This difference follows from the weakness of the analytical model. However, considering that wall duct temperature is reconstructed very well and small temperature differences, $D T$, are present it could be stated that the numerical model works correctly, and results are close to the exact analytical solution. In the following step the described model was modified and the domain was extended to include solid wall material. The results obtained with the aid of modified model were compared with experimental results. That is shown in the following Section. 

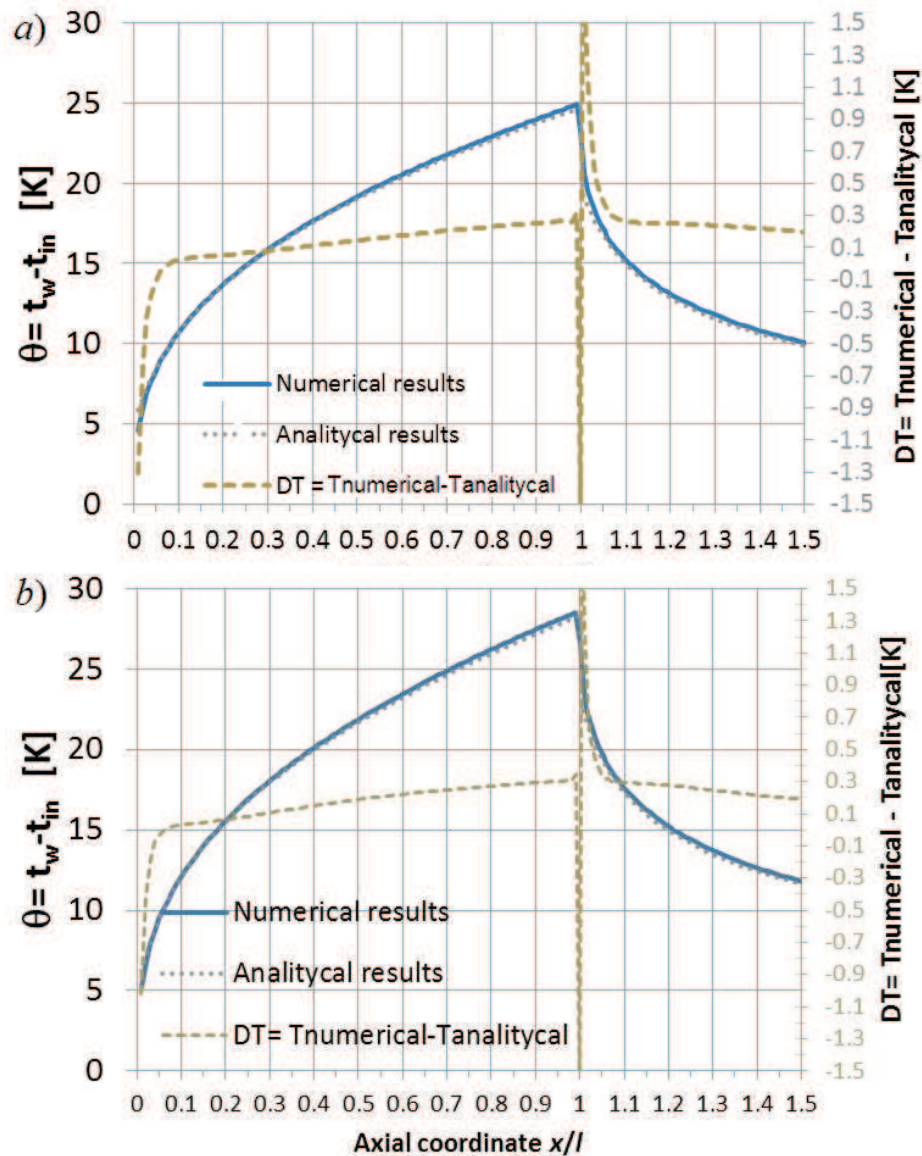

Figure 5: Numerical model wall temperature distribution and comparison with analytical results: a) $\operatorname{Re}=180$, b) $\operatorname{Re}=235$.

\section{Experimental results}

Research stand for testing thermal flow meter was designed and manufactured. The main parts of the research stand are: cooper pipe DN7, electric heater, and thermocouples $\mathrm{NiCr}-\mathrm{Ni}$. The main goal of the undertaken actions was to develop the dependency for water mass flow rate in terms of temperature difference measured in point located on the pipe outer surface upstream and downstream the heater. 


\subsection{Thermal flow meter and experimental research stand}

The thermal flow meter is made of copper pipe with the following dimensions: total length $L_{T}=500 \mathrm{~mm}$, inner diameter $D=7 \mathrm{~mm}$ and outer diameter $D_{\text {out }}=10 \mathrm{~mm}$. A band heater is applied which has a power of $50 \mathrm{~W}$ and voltage $24 \mathrm{~V}$ AC. The heater is made in the form of a cylinder, and the dimensions are length $L_{h}=50 \mathrm{~mm}$, inner diameter $10 \mathrm{~mm}$ and outer diameter $23 \mathrm{~mm}$. The designed flow meter is presented in Fig. 6. The band heater is fixed using two screws as it is depicted in Fig. 7.

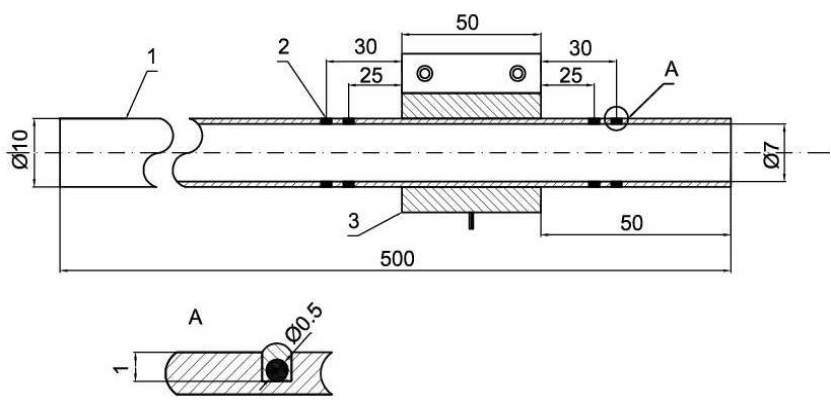

Figure 6: Scheme of the analyzed thermal mass flow meter: 1 - copper pipe, 2 - TC, 3 - heater.

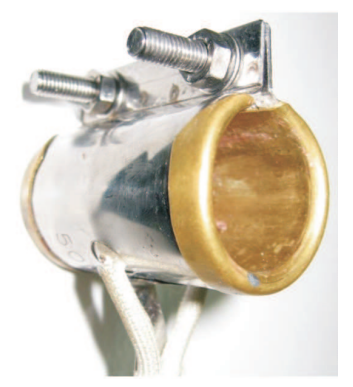

Figure 7: Band heater.

In order to measure outer pipe wall temperature the thermocouples (TCs) of type $\mathrm{K}$ were installed. The $\mathrm{NiCr}-\mathrm{Ni}$ thermocouples have a diameter of $0.5 \mathrm{~mm}$ and have been previously checked and properly calibrated. The grooves of $1.0 \mathrm{~mm}$ height and width were machined on the pipe circumference. In these groves TCs were installed and soldered. This solution should ensure the measurements accuracy and reduce the contact resistance between thermocouples and the pipe. Incisions are placed on both sides of the heater with the distance $25 \mathrm{~mm}$ and $30 \mathrm{~mm}$. Then TCs were once wrapped around the pipe to place wires along isotherms (Fig. 8). Such flowmeter equipped with TCs was installed in the research stand. The stand is depicted in Fig. 9. Distilled water is stored in a water container, and a water pump forces the flow. Auto transformer controls the output of the electric heater. All TCs are plugged into a data acquisition system, which stores all measured data. The copper pipe that undergoes measurements is well thermally isolated with mineral wool with a thickness of $20 \mathrm{~mm}$. The layer of mineral wool was additionally covered with foam insulation with a thickness of $5 \mathrm{~mm}$. Apart from the temperature measurements of pipe surface and 


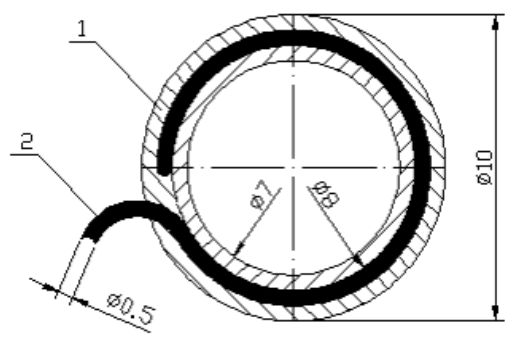

Figure 8: Diagram of installed thermocouple.

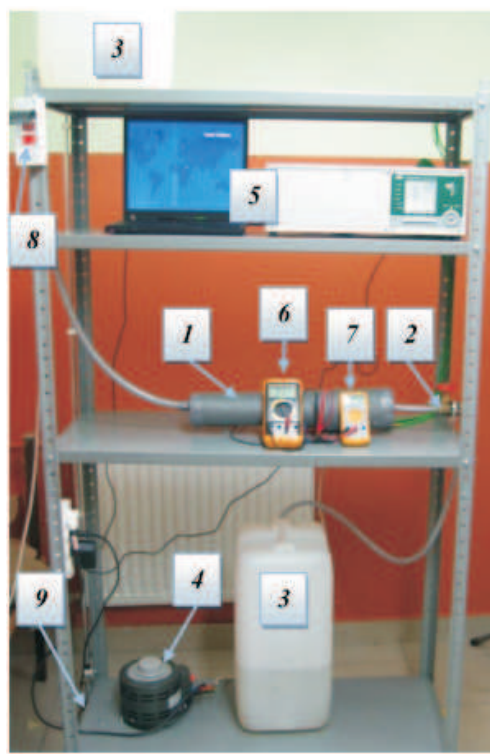

Figure 9: Thermal flow meter test stand: 1 - mass flowmeter, 2 - valve, 3 - water container, 4 - autotransformer, 5 - data acquisition system, 6 - ammeter, 7 voltmeter, 8 - switch, 9 - pump.

water at the mass flow meter inlet a water mass flow rate was measured as well. A control valve was install to control amount of flowing water through the flow meter.

\subsection{Test results}

During the tests water flow rate was regulated by the control valve. Measurements were performed in the laminar flow regime for Reynolds number in the range $100<\operatorname{Re}<2300$. Water mass flow rate was measured in two ways by laboratory mass flow meter and for the double check by measuring the volumetric flow rate. measuring the time of filling a calibrated container. The TCs have nomenclature as shown in Fig. 10. The temperature differences, $\Delta T$, which are used to develop dependencies of mass flow rate $(\dot{m})$ on the temperature differencies, have formulas as follows $\Delta T_{25}=T_{2}-T_{1}$ and $\Delta T_{35}=T_{4}-T_{1}$ (Fig. 10). The applied heater (Fig. 7) has a power of 

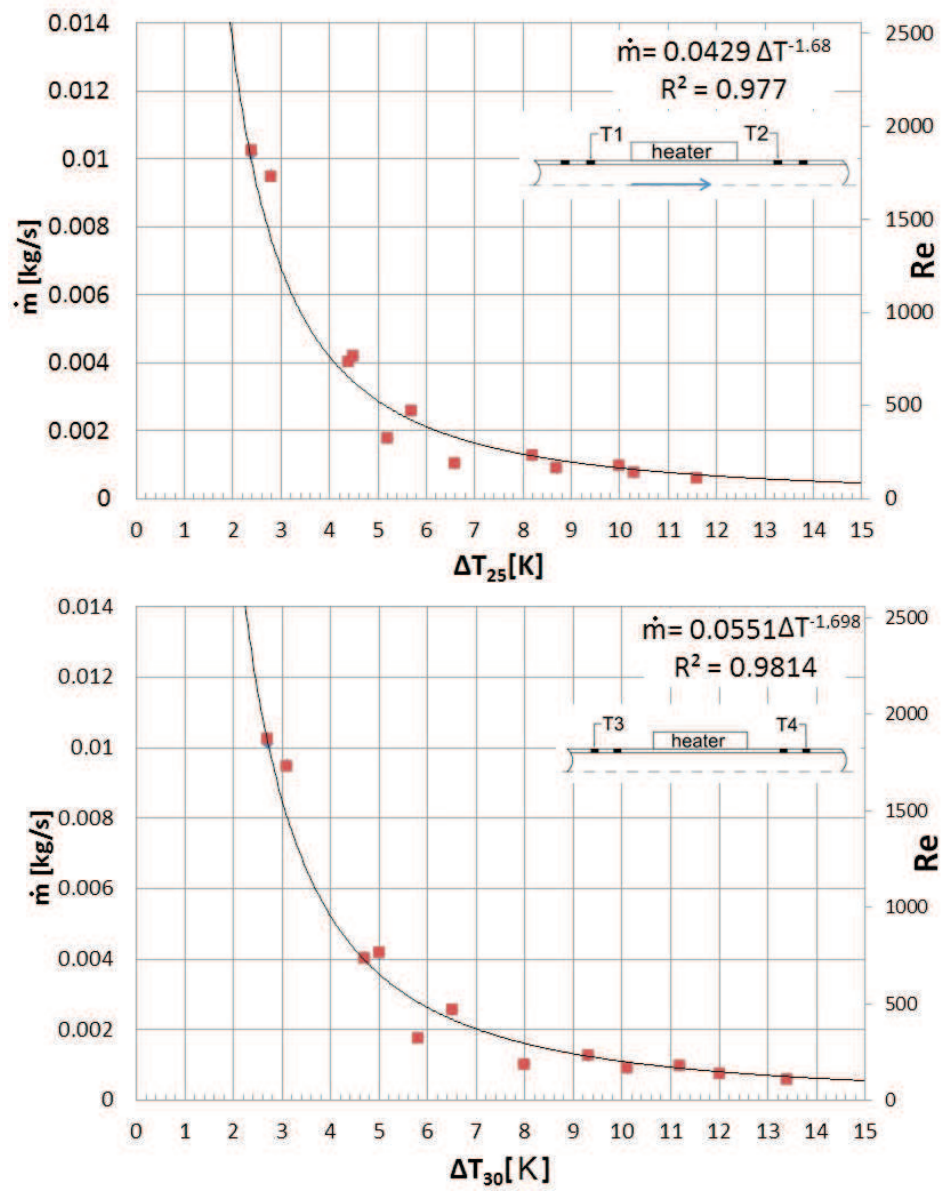

Figure 10: Measurements results and regression functions mass flow rate vs. temperature difference.

$50 \mathrm{~W}$ what gives heat flux value $q=31900 \mathrm{~W} / \mathrm{m}^{2}$.

The measurement results for TC located $25 \mathrm{~mm}$ and $30 \mathrm{~mm}$ from heater are presented in Fig. 10. The main conclusion which follows from performed measurements is that the solid surface temperature decreases with increasing water flow rate. Additional test data were subjected to approximation and hence the regression functions were developed. Functions reconstruct the measured data well and a coefficient of determination $\mathrm{R}^{2}$ is equal to 0.98. From obtained results follows that water mass flow rate in laminar flow regime could be determined in terms of measured temperature differ- 
ence. To increase the instrument sensitivity the heat flux value should be increased.

Finally, experimental results were compared with numerical model results. The numerical model described in Section 3 was modified and pipe wall thickness was added to the calculation procedure. Conjugated heat transfer phenomena were analyzed to model the flow meter. Figure 11 shows the results of comparison, solid line represents approximated measurements results while the dash line shows the numerical results.

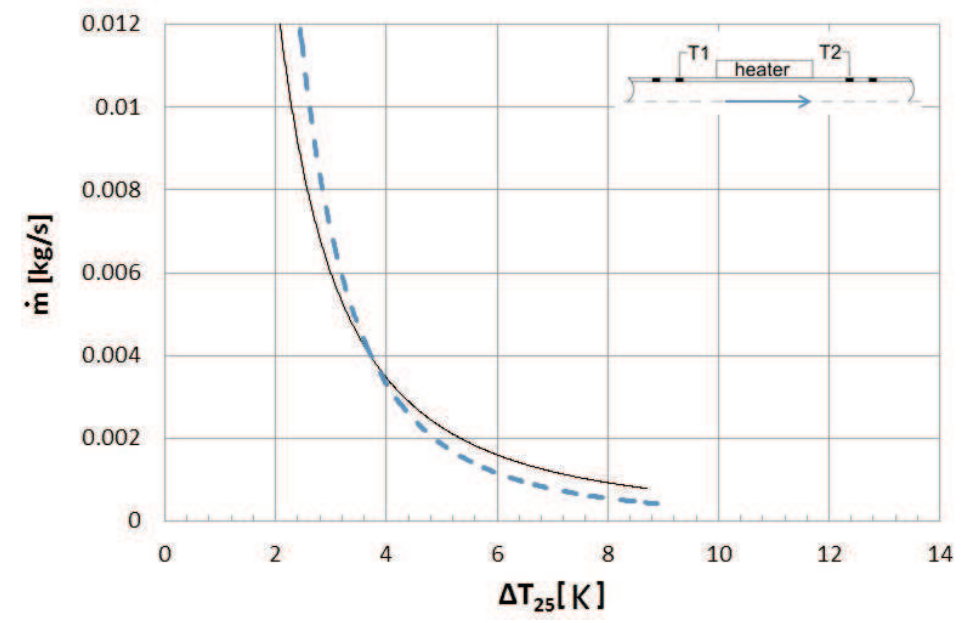

Figure 11: The comparison of numerical results (dashed line) with experimental measurement (solid line).

The comparison shows that numerical model reflects the results of measurements very well. This makes possible to state that the numerical model was validated and makes it possible to perform subsequent numerical tests of the flow meter.

\section{Summary}

The heat transfer phenomenon that takes place when water flows through the heated pipe was studied using experimental, numerical and analytical methods. The numerical and analytical model is applied to estimate wall duct temperature profile from the heated part of the pipe and not heated downstream element as well. The numerical model is further modified; the wall duct thickness is added and verified by experimental results. The test 
results concerning the created water mass flow meter are presented. The presented results refer to the laminar fully developed flow with Re in range $100<\operatorname{Re}<2300$. The presented results show the technical possibility of implementing presented principle in water mass flow meter. The flow meter proved the ability to measure flow rate in terms of temperature difference, indicated by TCs located on the both side of the heater, in the range from 0 up to $0.01 \mathrm{~kg} / \mathrm{s}$. The flow meter sensitivity could be changed by regulation of the heater power. Obtained results are important for analyzing flow meters and are the solid background for further research concerning its application to liquid flow.

Received 9 November 2015

\section{References}

[1] SAzhin O.: Novel mass air flow meter for automotive industry based on thermal flow microcrosensors. II flow meter, test procedure and results. Flow Measur. Instrum 35(2014), 48-54.

[2] Cha'o-Kunang C., Li-Wen W., Yue-Tzu Y.: Application of the inverse method to the estimation of heat flux and temperature on the external surface in laminar pipe flow. Appl. Therm. Eng. 26(2006), 1714-1724.

[3] Farzaneh-Gord M., Parvizi S., Arabkoohsar A., Machado L., Koury R.N.N.: Potential use of capillary tube thermal mass flow meter to measure residential natural gas consumption. J. Nat. Gas Sci. Eng. 22(2015), 540-550.

[4] Siegel R., Sparrow E.M., Hallman T.M.: Steady laminar heat transfer in a circular tube with prescribed wall heat flux. App. Sci. Res. Sec A., 7(1958), 386392.

[5] Ghiahiann S.M.: Convective Heat and Mass Transfer. Cambridge University Press, Cambridge 2011.

[6] Hsu C.J.: Heat transfer in a round tube with sinusoidal wall heat flux distribution. AIChE J. 11(1965), 690-695. 